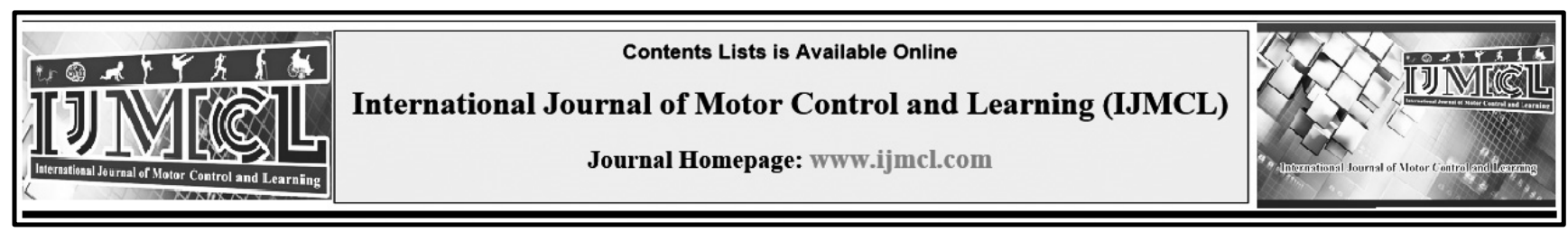

\title{
True Championship: What We Stand to Lose in Our Obsession to Win
}

\author{
Mohammad Khabiri ${ }^{a *}$ \\ ${ }^{a}$ Associate Professor, Department of Sport Psychology, University of Tehran, Tehran, Iran \\ * Corresponding E-mail: mkhabiri@ut.ac.ir \\ Received: 2019/07/25 \\ Accepted: 2019/10/09 \\ Published: 2019/11/19
}

\section{DEAR EDITOR}

With a mission to preserve the integrity of competition, inspire a commitment to the core principles of true championship, and protect the rights of Iranian athletes to compete and fair play. In this mission true competition holds out as sport is played fair, by the rules, with respect for oneself as well as for competitors, coaches, and officials, and the joy of competition and achievement with the fulfillment of challenge, participation, and Sportsmanship.

Angry club managers, coaches, and spectator's behavior at youth sport events is increasingly documented and studied (Omli \& LaVoi, 2009). Gould et al (2004) surveyed 154 varsity high school coaches across seven sports and found that problems with parents were frequent (Gould \& Carson, 2004). Kidman et al (1999) found that parents yell most at their own children during competitions (Kidman, McKenzie, \& McKenzie, 1999). Harris (2004) in Interactive survey of 18- year old involved in organized sport revealed that 31 percent had seen parents yelling at or arguing had seen parents yelling at or arguing with officials, and 28 percent saw parents yelling at or arguing with coaches ("Harris Interactive," 2004).

Certainly, everyone who plays sport at any level wants to win that is the nature of all competition. But, the indicators of our society that aims to win at any and all costs are plentiful. Intolerant clubs' managers, coaches, athletes who use performance-enhancing drugs or otherwise break the rules, from internal part, and fans, athletes' parents, and media, from external part, all have great obsession to win. This obsession to win causing a lot of psychological pressure on the shoulder of athletes. It should be noted that almost all athletes experience psychological pressure or nervousness at some time or another during their athletic careers. This is not normal but it should be expected. However, it is the chronic psychological pressure, lack of confidence, pre-competition 
jitters, and other thoughts and emotions that keep athletes from reaching their full potential. Therefore, it seems imperative that both coaches and athletes be made aware of the mental preparation strategies for dealing with these psychological factors that can adversely affect performance. However, before this can be done it is necessary to know how our thought can influence our attitudes and emotions. Because thoughts can influence performance and both coaches and athletes generally acknowledge the important role that thoughts play in achieving high level of performance.

More recently, researchers have provided experimental, correlational, and anecdotal evidence that patterns of thought can influence athletic performance.

Specifically, cognitive behavior modification theory maintains as its basic premise that there is continuity between an individual's thoughts and his or her overt behavior. In essence, improper thought on a regular basis (e.g., "I have to be champion at any and all costs ") can result in undesirable behavior.

We, as a club manager or a coach, need to create a cultural shift to renew the true spirit of sport. Sport takes place in an environment that has been severely and unclean by scandals and cheats, and the question remains regarding how this generation of sport players will be remembered.

Well-founded concerns about sport focus on the overemphasis on winning, specialization, and commercialization, as well as the under emphasis on ethics. This gives us signals the critical need for a cultural shift in how we experience and value sport. The foundation of such a movement should include strategy and action plan that advance fairness, excellence, inclusion, and fun and that promote ideas that enable us as individual citizens, clubs, teams to work toward achieving sportsmanship and FairPlay beside true championship ("U.S. Anti-Doping Agency (USADA)," 2012).

\section{References}

1. Gould, D., \& Carson, S. (2004). Fun \& games? Myths surrounding the role of youth sports in developing Olympic champions. Youth Studies Australia, 23(1), 19.

2. Harris Interactive. (2004). Youth and Sports. Trends and Tudes, 3(9), 3.

3. Kidman, L., McKenzie, A., \& McKenzie, B. (1999). The nature of target of parents' comments during youth sport competitions. Journal of sport behavior, 22(1), 54.

4. Omli, J., \& LaVoi, N. M. (2009). Background anger in youth sport: A perfect storm. Journal of sport behavior, 32(2), 242-260.

5. U.S. Anti-Doping Agency (USADA). True Sport. (2012). 